\title{
Cooperation between Hsp90 and mortalin/ GRP75 in resistance to cell death induced by complement C5b-9
}

\author{
Perri Rozenberg', Lea Ziporen', Dana Gancz', Moran Saar-Ray and Zvi Fishelson (1)
}

\begin{abstract}
Cancer cells are commonly more resistant to cell death activated by the membranolytic protein complex C5b-9. Several surface-expressed and intracellular proteins that protect cells from complement-dependent cytotoxicity (CDC) have been identified. In this study, we investigated the function of heat shock protein 90 (Hsp90), an essential and ubiquitously expressed chaperone, overexpressed in cancer cells, in C5b-9-induced cell death. As shown, inhibition of Hsp90 with geldanamycin or radicicol is enhancing sensitivity of K562 erythroleukemia cells to CDC. Similarly, Hsp90 inhibition confers in Ramos B cell lymphoma cells elevated sensitivity to treatment with rituximab and complement. C5b-9 deposition is elevated on geldanamycin-treated cells. Purified Hsp90 binds directly to C9 and inhibits zincinduced C9 polymerization, indicating that Hsp90 may act directly on the C5b-9 complex. Mortalin, also known as stress protein 70 or GRP75, is a mitochondrial chaperone that confers resistance to CDC. The postulated cooperation between Hsp90 and mortalin in protection from CDC was tested. Geldanamycin failed to sensitize toward CDC cells with knocked down mortalin. Direct binding of Hsp90 to mortalin was shown by co-immunoprecipitation in cell extracts after triggering with complement as well as by using purified recombinant proteins. These results provide an insight into the protective mechanisms utilized by cancer cells to evade CDC. They suggest that Hsp90 protects cells from CDC by inhibiting, together with mortalin, C5b-9 assembly and/or stability at the plasma membrane.
\end{abstract}

\section{Introduction}

The complement system takes part in the systemic immune attack on abnormal cells, such as cancer cells, and in their elimination. To achieve effective cell death, the complement system assembles the C5b-9 membrane attack complex (MAC) that inserts into cell membrane and induces cell death ${ }^{1,2}$. The MAC is inflicting complement-dependent cytotoxicity (CDC) via several parallel mechanisms that are still not fully characterized. Elevated calcium ion levels have been shown to play a key role in the cell death ${ }^{3}$. In addition, the MAC is activating a pathway of programmed necrotic cell death involving JNK and $\mathrm{Bid}^{4,5}$.

\footnotetext{
Correspondence: Zvi Fishelson (lifish@post.tau.ac.il)

'Department of Cell and Developmental Biology, Sackler School of Medicine, Tel Aviv University, Tel Aviv 69978, Israel

Edited by H.-U. Simon
}

To resist the potential toxic effects of the C5b-9 complex, cells utilize several ubiquitously expressed membrane complement regulators, membrane cofactor protein/CD46, decay accelerating factor/CD55 and CD59 $9^{6}$. Cancer cells overexpress these proteins and thus become increasingly resistant to $\mathrm{CDC}^{7}$. Targeting of antibodies or siRNA to these membrane regulators on cancer cells increases their sensitivity to complement attack $^{8,9}$. Cells also actively remove the C5b-9 complexes from their surface through endocytosis and exovesiculation ${ }^{10}$. Additional protection from $C D C$ is conferred by the mitochondrial chaperone mortalin/GRP $75^{11}$. Mortalin is a constitutively expressed member of the heat shock protein 70 family located primarily in mitochondria and secondarily in other cellular compartments ${ }^{12,13}$. Elevated levels of mortalin were reported in cancer cells ${ }^{14-16}$. Inhibition of mortalin synthesis or activity is sensitizing 

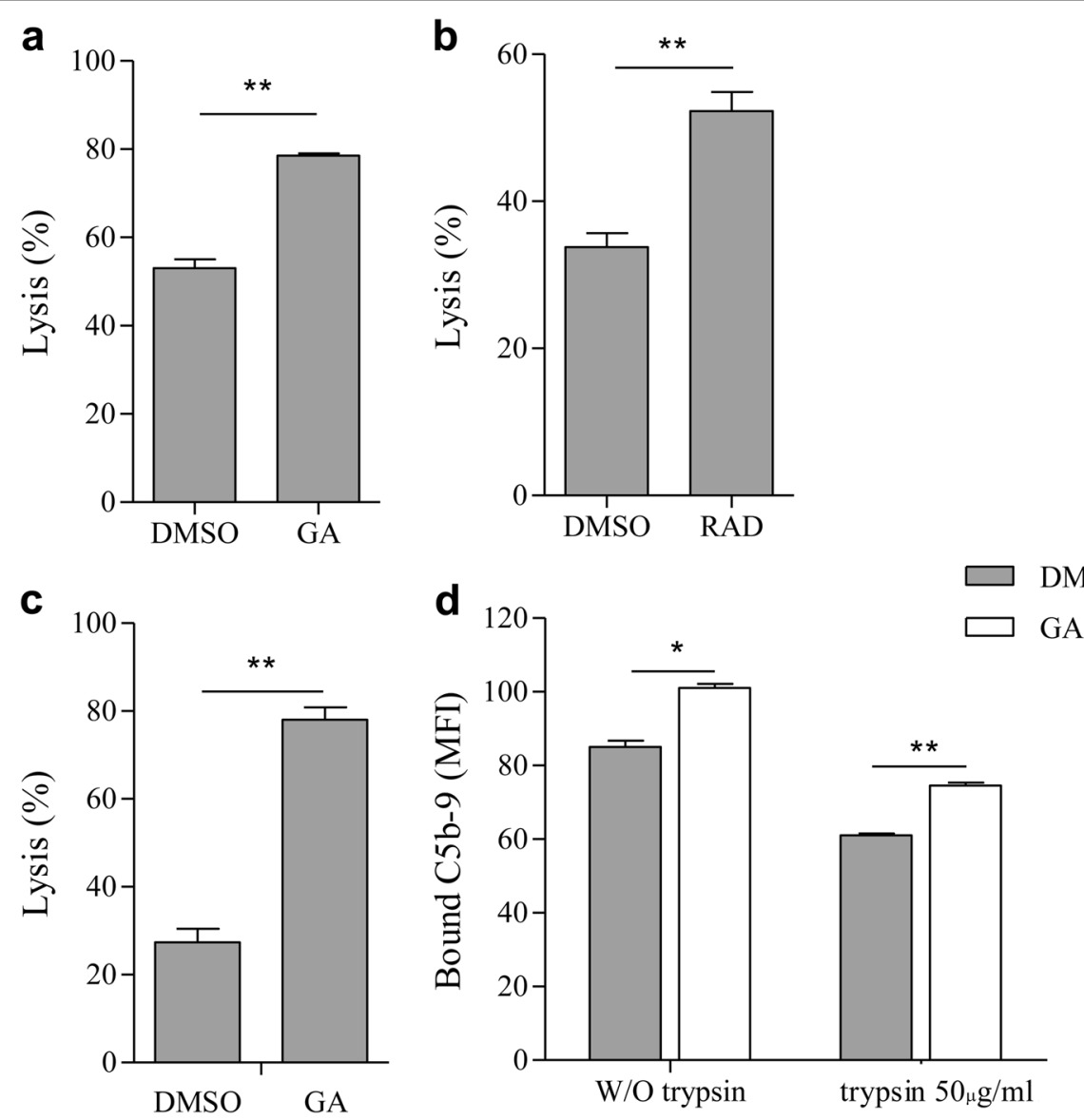

Fig. 1 Hsp90 inhibitors sensitize cells to CDC. a, b K562 cells were incubated with geldanamycin (GA, $100 \mu M)(\mathbf{a})$ or radicicol (Rad, $100 \mu M)$ or with DMSO (0.5\%) as control for $60 \mathrm{~min}$ at $37^{\circ} \mathrm{C}$. Then, the cells were washed and treated with antibody and NHS for 60 min at $37^{\circ} \mathrm{C}$. Percent lysis was determined by propidium iodide inclusion. c Ramos cells were incubated with geldanamycin (GA, $100 \mu \mathrm{M})$ or with DMSO (0.5\%) as control for 60 min at $37^{\circ} \mathrm{C}$. Then, the cells were washed and treated with rituximab $(3 \mu \mathrm{g} / \mathrm{ml})$ and NHS (50\%) for $60 \mathrm{~min}$ at $37^{\circ} \mathrm{C}$. Percent lysis was determined by propidium iodide inclusion. d K562 cells were treated with geldanamycin or with DMSO for $60 \mathrm{~min}$, followed by antibody (30 min) and NHS (10 min, peak C5b-9 formation). The cells were then treated or not with trypsin and labeled with aE11 monoclonal antibody followed by a secondary FITClabeled antibody. Mean fluorescence intensity (MFI) of bound C5b-9, representative of three independent experiments, is presented. ${ }^{*} P<0.05,{ }^{* *} P<$ 0.01

cells to $\mathrm{CDC}^{17}$. Mortalin contributes to the shedding of C5b-9 complexes from cells in membrane vesicles and was shown to bind directly to complement $C 9^{11,18}$.

Heat shock protein 90 (Hsp90) plays essential roles in cell signaling, protein folding and maturation, and cell proliferation and survival ${ }^{19-21}$. Two genes encode for the cytoplasmic Hsp90, HSP90AA1 encoding for an inducible Hsp90 $\alpha$, and HSP90AB1 encoding for the constitutively expressed Hsp90 $\beta^{22}$. Two Hsp90 isoforms are located in the endoplasmic reticulum (Grp94) and the mitochondria (TRAP1 $^{23,24}$. In cancer, Hsp90 expression is upregulated and proposed to be involved in cancer initiation and progression $^{25-27}$. Hsp90 upregulation correlates with bad prognosis in solid tumors and leukemia ${ }^{28}$. Hsp90 is primarily located in the cytosol and to some extent in the nucleus. However, it is also abundant in mitochondria of cancer cells and is protective, together with TRAP1, in mitochondrial cell death ${ }^{29}$. Due to its numerous cellular vital functions, Hsp90 has been exploited for several years as a target in cancer therapy and small molecule Hsp90 antagonists are being examined in clinical trials ${ }^{30}$. Inhibition of Hsp90 was shown to confer on human cancer cells sensitivity to serum lysis ${ }^{31}$. Here, we have examined the protective effect of Hsp90 against CDC. The possible association between $\mathrm{Hsp} 90$ and mortalin in protection was investigated. Our results demonstrate that Hsp90 plays a role in cell protection from CDC and that mortalin takes part in this protection. A direct protein-protein interaction between Hsp90 and mortalin is shown, as well as an interaction between $\mathrm{Hsp} 90$ and complement protein C9. A role for Hsp90, in collaboration with mortalin, in the diminution of the number of C5b-9 complexes stably 
a $\mathrm{Hsp}_{90}+\mathrm{BSA}$

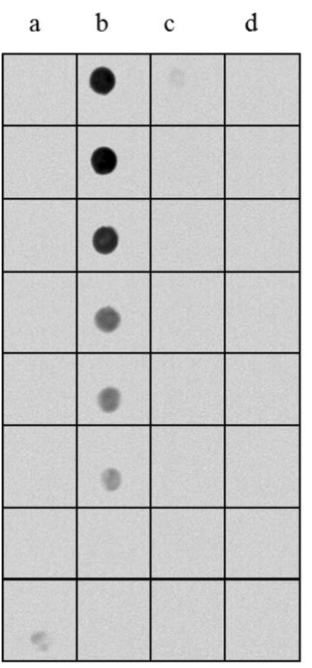

b

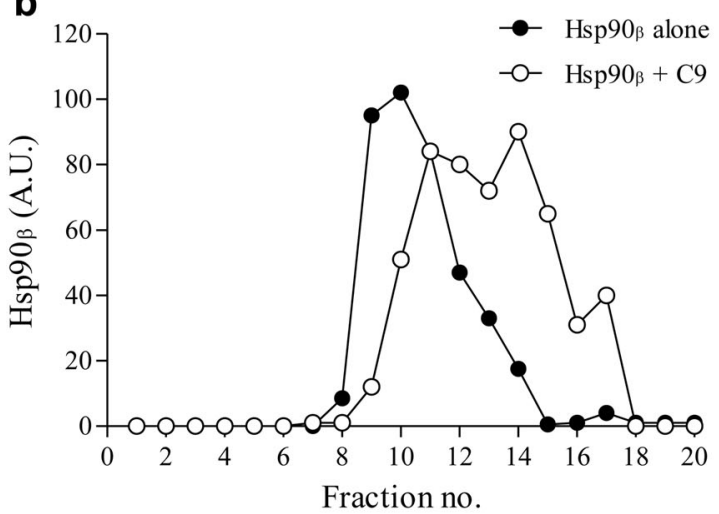

C

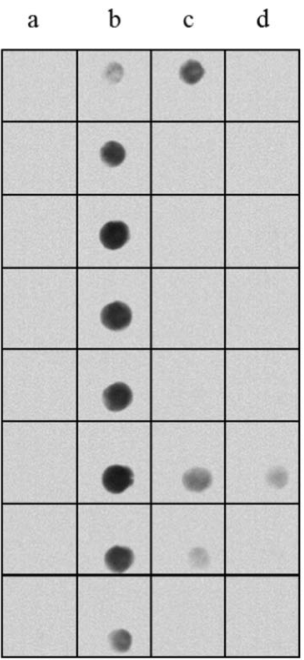

P

- $\mathrm{Hsp} 90_{\beta}$ alone - $\mathrm{Hsp} 90_{\beta}+\mathrm{C} 9$

d
C9 + Hsp90 ${ }_{\beta}$
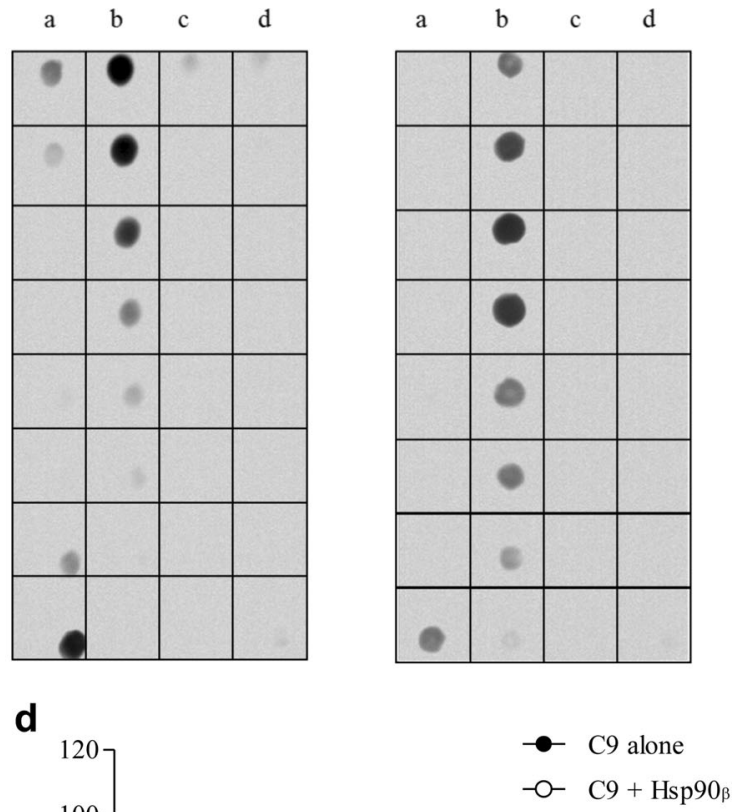

e

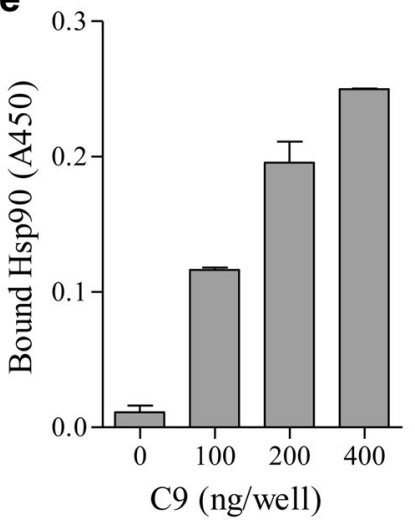

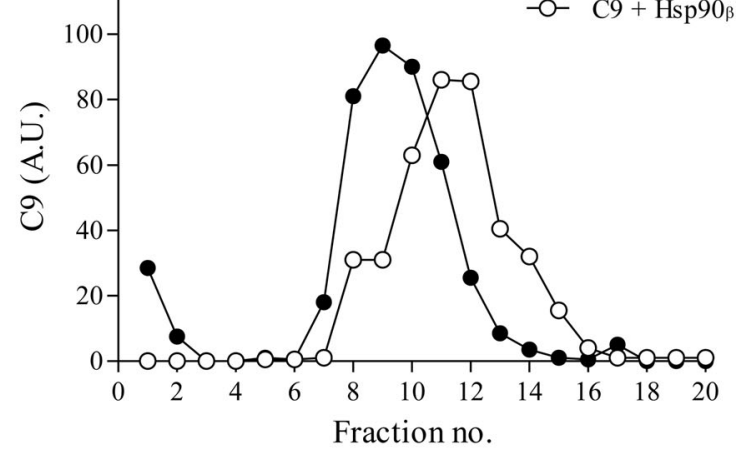

f

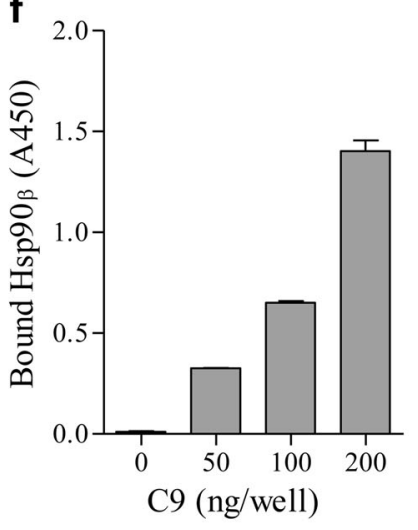

Fig. 2 Interaction of Hsp90 with C9. a-d Hsp90ß-C9 binding was tested by co-sedimentation through sucrose gradients. Recombinant Hsp90ß was incubated with C9 (1 $\mu \mathrm{g}$ each) for $1 \mathrm{~h}$ at $37^{\circ} \mathrm{C}$. The samples were layered on top of $13 \mathrm{ml}$ of 10-30\% sucrose density gradients that were subjected to unltracentrifugation for $18 \mathrm{~h}$ at 40,000 rpm. Fractions $(300 \mu \mathrm{l})$ were collected from the gradient top. Samples $(90 \mu \mathrm{l})$ from each fraction were analyzed by dot blotting with anti-Hsp90 (a, b) or anti-C9 (c, d) antibody and a peroxidase-conjugated secondary antibody. Representative dot blots are shown (a, c). Density of each scanned dot was quantified in arbitrary units (A.U.). Relative distribution of Hsp90 (b) and C9 (d) in fractions 1-24 of the gradients is shown. e, $\mathbf{f}$ Microtiter plate wells were coated with recombinant C9 or BSA as control. Then, K562 cells lysates (e) or recombinant Hsp90 (f) were added to the wells for $60 \mathrm{~min}$ at $37^{\circ} \mathrm{C}$. Binding of cytosolic (e) and recombinant (f) Hsp90 was quantified (optical density, A450) with antiHsp90 antibodies, followed by peroxidase-conjugated secondary antibodies. Increasing quantities of C9 yielded higher Hsp90 binding ( $P<0.001$, one-way ANOVA) 
inserted during complement activation into the cell membrane is indicated.

\section{Results}

Inhibition of Hsp90 enhances cell sensitivity to CDC

The role of $\mathrm{Hsp} 90$ in protection of K562 cells from CDC was first examined with Hsp90 inhibitors. Cells were preincubated with either geldanamycin or radicicol or with DMSO as control for $60 \mathrm{~min}$ at $37^{\circ} \mathrm{C}$. The cells were then treated with rabbit anti-K562 antibody for $30 \mathrm{~min}$ at $4{ }^{\circ} \mathrm{C}$ and with NHS for $60 \mathrm{~min}$ at $37^{\circ} \mathrm{C}$. Cell lysis was determined by propidium iodide inclusion. Both geldanamycin (Fig. 1a) and radicicol (Fig. 1b) enhanced sensitivity of K562 cells to CDC. The effect of geldanamycin on sensitivity of B cell lymphocytic leukemia Ramos cells to lysis by the anti-CD20 antibody rituximab and complement was next tested. Like K562 cells, Ramos cells pretreated with geldanamycin expressed a markedly elevated sensitivity to CDC (Fig. 1c). Treatment of cells with geldanamycin or radicicol followed by antibody and heatinactivated NHS had no effect on cell viability (data not shown).

Elevated sensitivity to CDC may result from enhanced complement activation and C5b-9 deposition. Therefore, K562 cells were treated with geldanamycin or with DMSO for $60 \mathrm{~min}$, followed by antibody (30 min) and NHS (10 min, peak C5b-9 formation). The cells were then treated or not with trypsin to remove loosely bound C5b-9 and leave only membrane-inserted C5b-9 complexes, and the effect of geldanamycin on C5b-9 deposition was tested ${ }^{10}$. As shown in Fig. 1d, treatment with geldanamycin led to higher levels of C5b-9 deposition. This was evident both in untreated cells and in trypsin-treated cells

\section{Interaction between Hsp90 and complement C9 during complement attack}

Earlier findings of direct binding between mortalin and C $9^{11,18}$ raised the possibility of a direct interaction between Hsp90 and C9. Binding of purified Hsp90ß (the constitutively expressed form of Hsp90) to C9 was first examined by using density gradient centrifugation, as described under "Methods" section. Hsp90 $\beta$ was mixed with C9 or with BSA for $1 \mathrm{~h}$ at $37^{\circ} \mathrm{C}$. Each sample was layered on top of a sucrose density gradient (1-20\% sucrose) and subjected to ultra-centrifugation. Fractions were collected from the top of the gradient and samples from each fraction were analyzed by dot dotting with antibodies directed to Hsp90ß (Fig. 2a, b) or to C9 (Fig. 2c, d). As shown, Hsp90 $\beta$ and C9 mixed together reached denser fractions of sucrose, than when mixed with BSA, indicating that the two proteins interacted with each other and formed heavier complexes.

Direct binding of Hsp90 and C9 was also tested in an ELISA. First, microtiter plate wells were coated with C9 or
BSA. Then, K562 cell extracts were added to all wells for $1 \mathrm{~h}$ at $37^{\circ} \mathrm{C}$. Binding of cellular Hsp90 was quantified with monoclonal mouse anti-Hsp90 antibody and a peroxidase-conjugated goat anti-mouse IgG antibody. Non-specific binding of Hsp90 to BSA was quantified and subtracted from the binding to C9. A significant dosedependent specific binding of cellular native $\mathrm{Hsp} 90$ to C9 was observed (Fig. 2e). In addition, microtiter plate wells were coated with $\mathrm{C} 9$ or BSA and binding of recombinant Hsp90 $\beta$ was quantified as above. Non-specific binding of Hsp90 $\beta$ to BSA was subtracted from the binding to C9. Again, a significant dose-dependent binding of C9 to Hsp90 $\beta$ was observed (Fig. 2f).

The possibility that Hsp90, acting as a chaperone, is directly affecting C5b-9 complex formation was raised. The last step in the process of C5b-9 complex formation is C9 polymerization. This step can be recaptured in the tube in the absence of the C5b- 8 complex by incubating purified C9 with zinc ions for $2 \mathrm{~h}$ at $37{ }^{\circ} \mathrm{C}^{32}$. The effect of recombinant $\mathrm{Hsp} 90 \beta$ on $\mathrm{C} 9$ polymerization was tested. As control, we used heat-denatured $\left(15 \mathrm{~min}\right.$ at $\left.60^{\circ} \mathrm{C}\right) \mathrm{Hsp} 90 \beta$ (dHsp90). Indeed, the results clearly showed that Hsp90 $\beta$, but not denatured Hsp90 $\beta$, inhibited zinc-induced C9 polymerization (Fig. 3a). BSA was added as another control for Hsp90 $\beta$ and had no effect on C9 polymerization.

Finally, the postulated interaction of Hsp90 with C9 in cells exposed to a complement attack was examined by co-immunoprecipitation. Cell extracts prepared from K562 cells treated with a sublytic dose of antibody and NHS or HIS $\left(10 \mathrm{~min}\right.$ at $\left.37^{\circ} \mathrm{C}\right)$ were precipitated with antiHsp90 $\beta$ antibodies or normal mouse IgG. The amount of immunoprecipitated C9 was quantified by western blotting. Hsp90-C9 binding was found in extracts of complement-treated cells after precipitation with antiHsp90 $\beta$ antibodies, but not in HIS-treated cells nor after precipitation with normal mouse IgG (Fig. 3b).

\section{Cooperation between Hsp90 and mortalin in cell protection from CDC}

Mortalin also plays a role in cell protection from $\mathrm{CDC}^{17}$. We examined whether it acts together with Hsp90 in the same protective pathway. If Hsp90 and mortalin act together, geldanamycin should have no effect on CDC after knocking down of mortalin. K562 cells were transfected with mortalin siRNA or with a scrambled siRNA. The expression level of mortalin in cells transfected with mortalin siRNA was indeed reduced (Fig. 4a). As can be seen in Fig. 4b, geldanamycin increased sensitivity to CDC of cells transfected with scrambled siRNA. In contrast, sensitivity of cells with knocked down mortalin to CDC was not affected by treatment with geldanamycin.

Direct binding of Hsp90 and mortalin was tested in an ELISA. After coating microtiter plate wells with recombinant mortalin or BSA, K562 cell extract was added to 

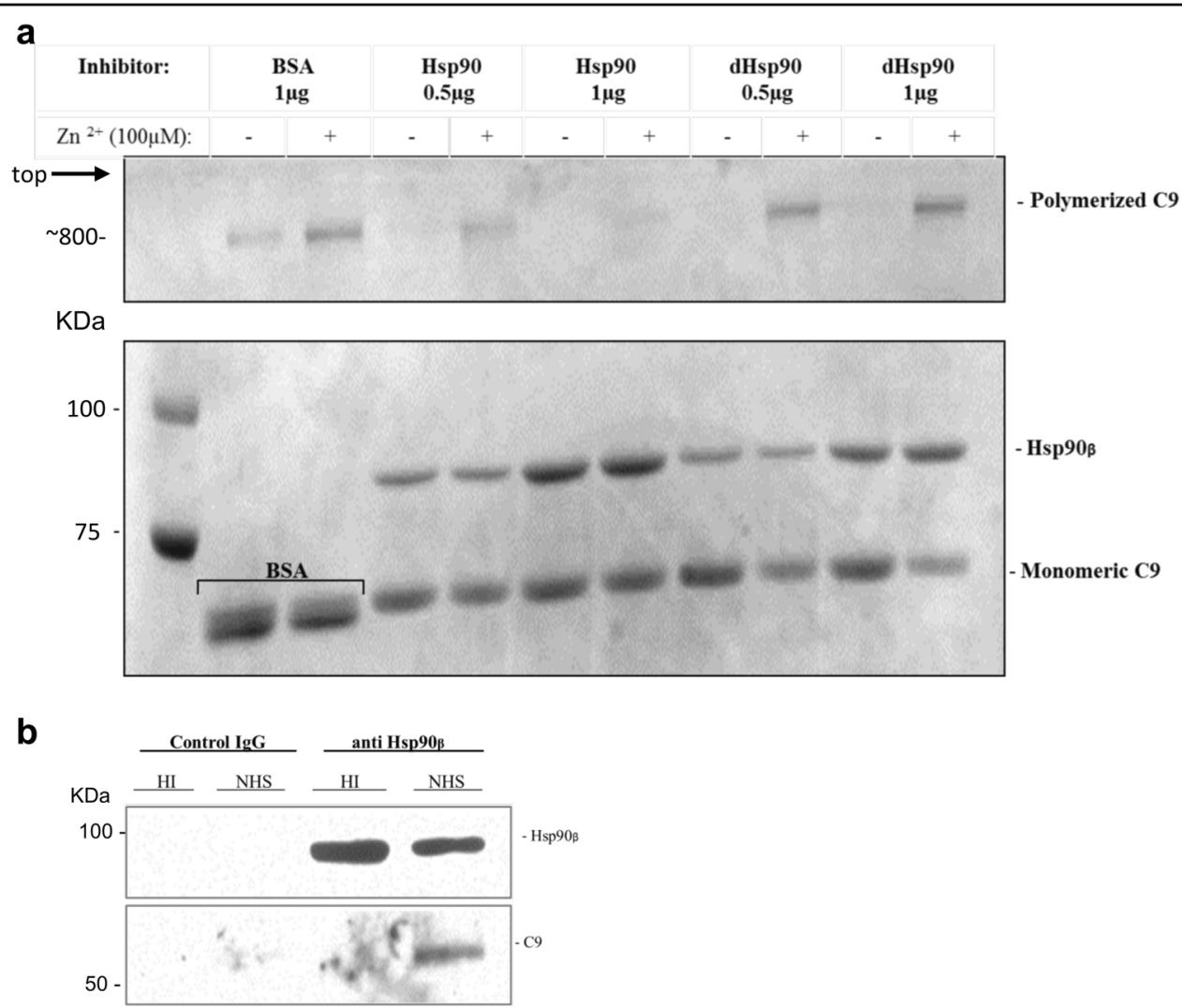

Fig. 3 Further indications for Hsp90-complement C9 interaction. a Hsp90 inhibits C9 polymerization. C9 (1 $\mu \mathrm{g})$ was mixed with recombinant Hsp90ß or heat $\left(60^{\circ} \mathrm{C}\right)$ denatured Hsp90ß (dHSP90), or BSA as control $(1 \mu \mathrm{g})$ and then incubated with or without $\mathrm{ZnCl} 2 \mathrm{for} 2 \mathrm{~h}$ at $37^{\circ} \mathrm{C}$. The samples were subjected to SDS-PAGE on a 3-10\% acrylamide gradient gel and stained with Coomassie blue. The bands of poly C9, monomeric C9, and Hsp90ß are indicated. b Cell lysates after complement activation contain Hsp90-C9 complexes. K562 cells were incubated with a sublytic dose of anti-K562 antibody and with normal human serum (NHS) or heat-inactivated (HI) serum for $10 \mathrm{~min}$ at $37^{\circ} \mathrm{C}$. Cell lysates were prepared and then immunoprecipitated with mouse anti-Hsp90 antibody (or control mouse lgG) coupled to agarose beads. Proteins attached to the beads were examined by SDS-PAGE and western blotting. Detection was with anti-Hsp90 (upper) and anti-C9 (lower) antibodies

the wells for $1 \mathrm{~h}$ at $37^{\circ} \mathrm{C}$. After washes, Hsp90 in wells was quantified with mouse anti-Hsp90 antibodies and peroxidase-conjugated goat anti-mouse IgG antibody. Non-specific binding of $\mathrm{Hsp} 90$ to BSA was also quantified and subtracted from the binding to mortalin. A significant dose-dependent binding of cellular native Hsp90 to mortalin was observed (Fig. 4c). In addition, microtiter plate wells were coated with recombinant Hsp90 $\beta$ or BSA and binding of recombinant His-tagged mortalin was quantified. Non-specific binding of mortalin to BSA was subtracted from the specific binding to Hsp90 $\beta$. Again, a significant dose-dependent binding of mortalin to Hsp90 $\beta$ was observed (Fig. 4d).

We next examined whether C5b-9-induced stress activates an association between mortalin and Hsp90. In support, mortalin-Hsp90 binding was demonstrated in K562 cells by co-immunoprecipitation after complement activation for $10 \mathrm{~min}$ (Fig. 4e). A small amount of mortalin was retained on agarose beads coated with normal mouse IgG. However, the quantity of mortalin immunoprecipitated with anti-Hsp90 antibodies markedly increased in cells subjected to a sublytic dose of antibody and complement (NHS).

Competition between mortalin and Hsp90 on binding to C9 was tested in a competitive ELISA. Microtiter plate wells were coated with $C 9$. Then, recombinant mortalin pre-mixed with increasing amount of $\mathrm{Hsp} 90 \beta$ or BSA was added to each well for $1 \mathrm{~h}$ at $37^{\circ} \mathrm{C}$. Binding of mortalin was quantified with monoclonal mouse anti-mortalin antibody and a secondary peroxidase-conjugated goat anti-mouse IgG antibody. The results clearly showed that Hsp90 $\beta$ competed with mortalin, in a dose-dependent manner, on binding to C9 (Fig. 4f). BSA had no effect on mortalin-C9 interaction.

\section{Discussion}

As shown here, Hsp90 protects K562 cells from necrotic cell death activated by antibody and complement. 


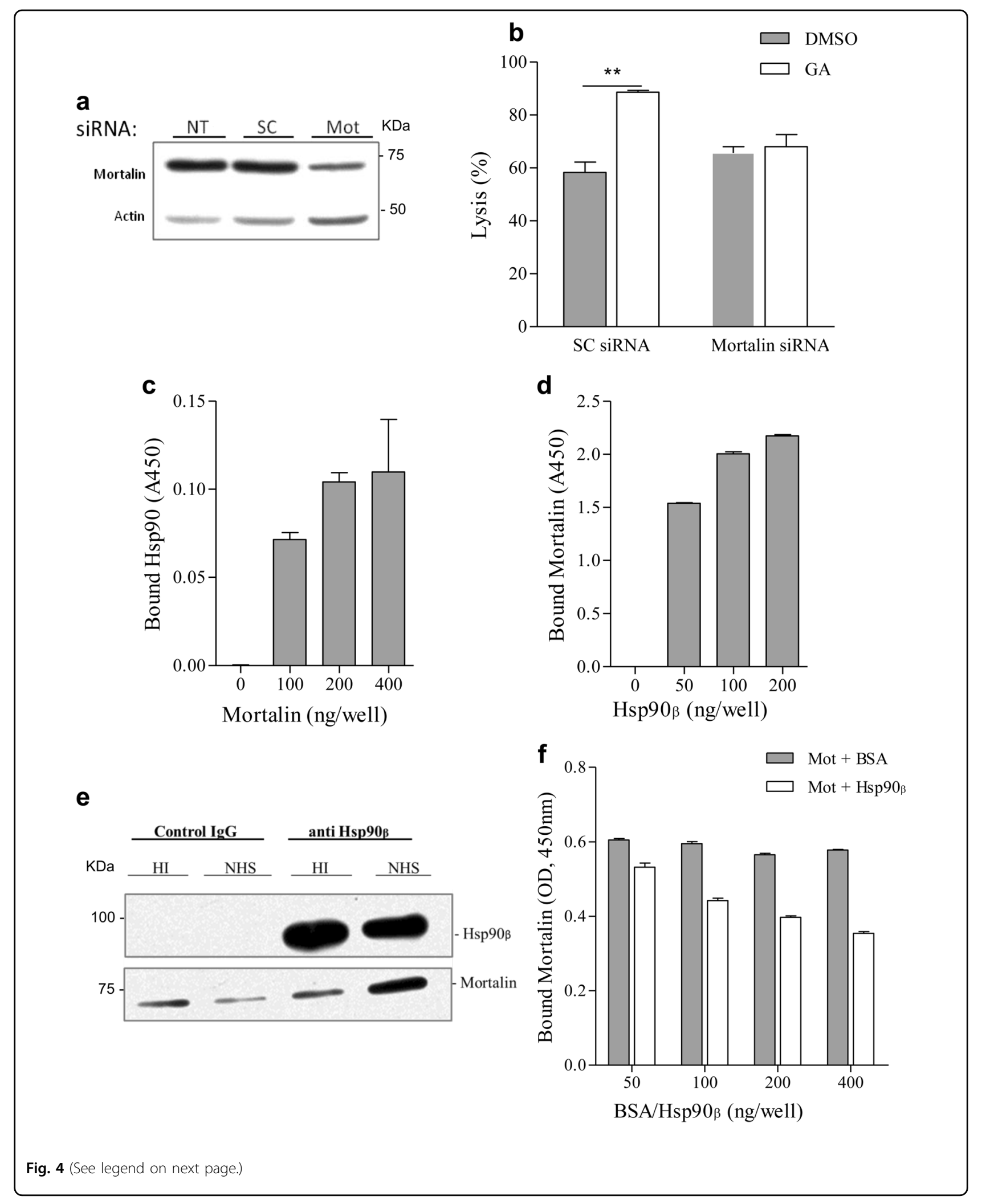


(see figure on previous page)

Fig. 4 Collaboration between mortalin and Hsp90 in complement resistance. a, b K562 cells were transfected with mortalin siRNA (Mot) or a non-specific siRNA (SC). After $48 \mathrm{~h}$, the level of mortalin in the cells was examined by SDS-PAGE and western blotting with anti-mortalin antibody and with anti-actin antibodies (a). Transfected cells were treated with GA $(100 \mu \mathrm{M})$ or DMSO and then subjected to treatment with antibody and NHS. Percent lysis was determined by propidium iodide inclusion (b). NT non-treated. $\mathbf{c}$, d Microtiter plate wells were coated with recombinant mortalin (C) or Hsp90ß (D) or BSA as control (0). Then, K562 cells lysates (c) or recombinant mortalin (d) were added to the wells for 60 min at $37^{\circ} \mathrm{C}$. Binding of Hsp90 (c) was quantified (optical density, A450) with anti-Hsp90 antibodies and binding of His-tagged mortalin (d) was detected with anti-His antibodies, both followed by peroxidase-conjugated secondary antibodies. A dose-dependent binding of Hsp90 and mortalin was observed $(P<0.05$ (c), $P<0.001$ (d), one-way ANOVA). e K562 cells were incubated with a sublytic dose of anti-K562 antibody and with normal human serum (NHS) or heat-inactivated $(\mathrm{HI})$ serum for $10 \mathrm{~min}$ at $37^{\circ} \mathrm{C}$. Cell lysates were prepared and then immunoprecipitated with mouse anti-Hsp90 antibody (or control mouse lgG) coupled to agarose beads. Proteins attached to the beads were examined by SDS-PAGE and western blotting. Detection was with antiHsp90 (upper) or anti-mortalin (lower) antibodies. f Microtiter plate wells were coated with C9 (100 ng/well) overnight. Mortalin was mixed with Hsp90ß or BSA and added to the wells. Binding of His-tagged mortalin to C9 was quantified with anti-His (mortalin) antibodies and peroxidaseconjugated secondary antibodies. Mortalin-C9 binding was significantly inhibited by Hsp90 $\beta$ but not by BSA $(P<0.001$, two-way ANOVA)

Complement-dependent cytotoxicity of $\mathrm{K} 562$ cells is markedly enhanced by inhibition of Hsp90 with geldanamycin or radicicol. Geldanamycin and radicicol that act as ATP mimetics inhibit Hsp90 by binding to its ATPase site $^{33,34}$. Hsp90 is a major cytosolic chaperone, yet in cancer cells it accumulates also in mitochondria ${ }^{29}$. This raises the possibility that both cytosolic and mitochondrial Hsp90 are involved and perhaps cooperate in protection of cells from the damages inflicted by the complement C5b-9 complexes. Indeed, mitochondrial damage is one of the earlier intracellular damages observed in cells undergoing $\mathrm{CDC}^{35}$. Mitochondrial Hsp90 was shown to confer upon cancer cells cell death resistance by suppressing the mitochondria-initiated calcium-mediated interorganelle stress response ${ }^{36}$. It is reasonable to assume that Hsp90 similarly protects mitochondria from CDC in cells injured by membranebound lytic C5b-9 complexes.

A major mitochondrial chaperone that regulates cell stress induced by complement is mortalin ${ }^{11,17,18}$. Inhibition of mortalin with MKT-077 or by mRNA knockdown with specific siRNA amplifies cell sensitivity to CDC. Dual targeting of mortalin and Hsp90 was shown to increase the efficacy of cancer cell death by enhancing p53mediated apoptosis in hepatocellular carcinoma cells ${ }^{37}$. Binding of mortalin to the Hsp90 paralog in the endoplasmic reticulum Grp94 was reported ${ }^{38}$. Our results demonstrate cooperation between Hsp90 and mortalin in cell protection from complement attack. Upon knocking down of mortalin in K562 cells with siRNA, the cells become insensitive to CDC promoting activity of geldanamycin (Fig. 4b). Thus, Hsp90 inhibition is effective as long as mortalin is present. In its absence, the cells have alternative means of protection from $\mathrm{CDC}^{39}$. Interestingly, even though partial knockdown of mortalin by siRNA did not significantly increase percent cell death (Fig. 4b), it completely abrogated the Hsp90 protective activity. This suggests that Hsp90 anti-CDC protective activity is lost in the absence of mortalin, whereas, in contrast, mortalin has Hsp90-dependent and Hsp90independent anti-CDC protective activities. A more complete knockdown or specific inhibition of mortalin markedly enhances $\mathrm{K} 562$ cell sensitivity to $\mathrm{CDC}^{17}$.

For functional cooperation, do mortalin and $\mathrm{Hsp} 90$ bind to each other? As shown here by co-immunoprecipitation analysis (Fig. 4e), control cells show almost no mortalin-Hsp90 binding. However, a clear mortalin-Hsp90 interaction occurs within 10 min after a complement stress. Direct binding has also been confirmed with purified mortalin and Hsp90 $\beta$ (Fig. 4c, d). It still remains to be determined where in the cell do mortalin and Hsp90 associate and which other proteins and signals are involved in this interaction. Hsp90 chaperones play vital and pivotal roles in several cellular compartments and activities ${ }^{19,20}$. They interact with numerous cochaperones and client proteins that include other heat shock proteins, kinases, phosphatases, transcription factors, and other proteins ${ }^{40}$. The list of annotated interactions is extensive as presented in Picard's table of Hsp90 interactors (http://www.picard.ch/downloads/ Hsp90interactors.pdf) and Altieri's mitochondrial Hsp90 proteome analysis ${ }^{41}$. Mortalin can be added now to the list as a stress-associated Hsp90 binder. Since mortalin binds to Hsp60 too ${ }^{42}$, it is likely that for regulation of certain stress conditions, mortalin joins the mitochondrial multi-chaperone complex comprised of HSP60 and $\mathrm{HSP}^{43}$.

For protection from $\mathrm{CDC}$, cells continuously remove the C5b-9 complexes from their surface, a process that depends on mortalin ${ }^{11,17,18}$. Mortalin inhibition is leading to elevated C5b-9 deposition. Similarly, inhibition of Hsp90 with geldanamycin is also amplifying C5b-9 deposition on $\mathrm{K} 562$ cells (Fig. 1). Direct binding of Hsp90 $\beta$ to C9 was demonstrated in cell lysates and with purified proteins by using several techniques (Figs. 2 and 3). Like mortalin ${ }^{17}$, Hsp90 $\beta$ inhibits polymerization of purified C9 induced by zinc ions (Fig. 3a). Interestingly, Hsp90 $\beta$ competes with mortalin on binding to C9 
(Fig. 4f), suggesting that they both bind to the same site in C9. Concomitant binding of both Hsp90 and mortalin to C5b-9 may be envisaged as it contains an oligomer composed of several C9 molecules. In complementtriggered cells, Hsp90 $\beta$ and mortalin bind to each other and both are required for efficient protection from CDC. In support, protection was not achieved by geldanamycin in mortalin knockout cells. Hence, it is conceivable that C5b-9-induced formation of Hsp90-mortalin heterocomplexes is a prerequisite for efficient protection against C5b-9. Whether or not the major protective activity of the Hsp90-mortalin complexes is targeted at the C5b-9 complexes in the plasma membrane, still remains to be determined.

In conclusion, programmed necrotic signals activated by complement C5b-9 are apparently downregulated by several members of the heat shock protein family, including $\mathrm{Hsc}^{4} 0^{44}$, mortalin ${ }^{18}$, and as shown here, Hsp90. These chaperones are overexpressed in cancer, and thus act as major obstacles to attempts to achieve cancer cure by antibody/complement-based immunotherapy. Currently, major attempts are being made to use chaperones inhibitors as adjuvant therapy to chemotherapy. Blocking of these chaperones in cancer will likely also amplify the efficacy of anti-cancer therapeutic antibodies through enhanced complement-dependent cytotoxicity. Hence, it is proposed that cancer patients receiving antibody therapy may benefit from co-administration of an Hsp90 inhibitor. Furthermore, the findings open new venues for interference with CDC in clinical cases in which complement C5b-9 is pathogenic (e.g., antibody-based autoimmune and inflammatory diseases).

\section{Material and methods}

\section{Cells, sera, and reagents}

K562 human erythroleukemia cells and Ramos B cell lymphocytic leukemia cells were cultured in RPMI-1640 supplemented with $10 \%$ fetal calf serum, $2 \%$ sodium pyruvate, $1 \%$ glutamine, and $0.2 \%$ antibiotic-antimycotic mixure at $37^{\circ} \mathrm{C}$ and $5 \% \mathrm{CO}_{2}$. The cells were split every 24-48 $\mathrm{h}$ so that all experiments were performed with cells in their logarithmic growth phase. Normal human serum (NHS) was used as a source for complement. Venous blood drawing from normal volunteers received approval of the Ethical Committee of Tel Aviv University. Serum was prepared from the blood and stored immediately in aliquots at $-70^{\circ} \mathrm{C}$ until used. Heat-inactivated serum (HIS) $\left(45 \mathrm{~min}\right.$ at $56^{\circ} \mathrm{C}$ ) was also prepared and used as a negative control. C8-deficient human serum (C8D) was prepared from a C8 $\beta$-deficient patient as described ${ }^{45}$. Purified human C9 and recombinant human Hsp90 $\beta$ were purchased from Complement Technology Inc. (Tyler, TX) and StressMarq (Victoria, Canada), respectively. Recombinant human mortalin with a 6xhis-tag was prepared as described before ${ }^{17}$. Geldanamycin (from S. hygroscopicus), radicicol was purchased from Sigma-Aldrich (St Louis, $\mathrm{MO})$.

\section{Antibodies}

Polyclonal antiserum directed to K562 cells was prepared in rabbits and polyclonal anti-human C9 antiserum was prepared in goats. This received approval of the Tel Aviv University Animal Committee and the Israel Ministry of Health. Rituximab (MabThera) antibody was purchased from Roche Pharmaceuticals, Israel. Mouse monoclonal antibody anti-GRP75 (mortalin) and mouse monoclonal antibody anti-Hsp90 $\beta$ were from StressMarq. Mouse monoclonal antibody anti-Hsp90 was from StressGen (Farmingdale, NY). Mouse monoclonal antibody anti-6xHis was from Clontech (Mountain View, CA). Mouse monoclonal antibody anti-human C5b-9 (clone aE11) was from Dako (Glostrup, Denmark). Mouse monoclonal antibody anti-actin was from Millipore (Billerica, MA). Mouse IgG was purchased from Sigma (Rehovot, Israel). Peroxidase-conjugated goat antibody anti-mouse IgG, peroxidase-conjugated rabbit antibody anti-goat IgG and FITC-conjugated goat antibody antimouse IgG were from Jackson ImmunoResearch Laboratories (Baltimore, MD).

\section{Cell death measurement}

K562 or Ramos cells $\left(1 \times 10^{6}\right)$ were treated with rabbit anti-K562 antibody or rituximab, respectively, diluted in phosphate-buffered saline containing $1 \mathrm{mM} \mathrm{CaCl}_{2}$ and 1 $\mathrm{mM} \mathrm{MgCl}_{2}$ (PBS) for $30 \mathrm{~min}$ at $4{ }^{\circ} \mathrm{C}$. Next, NHS was added (final 50\%) for $60 \mathrm{~min}$ at $37^{\circ} \mathrm{C}$. The cells were washed by centrifugation $\left(250 \times g, 8 \mathrm{~min}, 4^{\circ} \mathrm{C}\right)$ and suspended in PBS containing $1 \mu \mathrm{g} / \mathrm{ml}$ propidium iodide (PI). The cells were analyzed by flow cytometry in a FACSort (Becton Dickinson, San Jose, CA). The percentage of dead cells (PI labeled cells) was determined (WINMDI software) and the percent of dead cells after antibody and HIS treatment was subtracted from that of antibody and NHStreated cells. Cell lysis was also determined microscopically by trypan blue exclusion (0.02\%). Mouse fibroblasts were subjected to cytotoxicity assays after trypsinization. Unlike human cells, mouse cells activate complement in the absence of exogenous antibodies. Therefore, fibroblasts cell death assays were performed with diluted NHS without added antibodies.

\section{Measurement of C5b-9 deposition and C9 polymerization}

K562 cells were treated with rabbit anti-K562 antibodies for $30 \mathrm{~min}$ at $4{ }^{\circ} \mathrm{C}$ and then with NHS for $10 \mathrm{~min}$ at $37^{\circ} \mathrm{C}$. To avoid adverse effects of cell death, a sublytic dilution of the antibodies (yielding 10-20\% cell death) was used. This was followed by treatment with trypsin (trypsin-TPCK, Sigma, $50 \mu \mathrm{g} / \mathrm{ml}$ ) (to remove loosely attached C5b-9 
complexes) or with PBS for $20 \mathrm{~min}$ at room temperature. For C5b-9 labeling, the cells were treated with aE11 monoclonal antibody ${ }^{46}$, followed by a secondary FITCconjugated antibody. Cells were analyzed by flow cytometry (Becton Dickinson, San Jose, CA). Mean fluorescence intensity of cells labeled with aE11 was determined with the WinMDI software.

Purified human C9 $(1 \mu \mathrm{g})$ was incubated in Tris- $\mathrm{HCl}$ buffer $\left(20 \mathrm{mM}\right.$, pH 7.2) containing with $100 \mu \mathrm{M} \mathrm{ZnCl}_{2}$ for $2 \mathrm{~h}$ at $37^{\circ} \mathrm{C}^{32}$. The samples were reduced with dithiothreitol $(150 \mu \mathrm{M})$ and subjected to SDS-polyacrylamide gel electrophoresis on a 3-10\% acrylamide gradient gel. The gel was stained with Coomassie blue.

\section{Cell extracts}

K562 cells treated with antibody and complement under sublytic conditions, as described above, were spun down by centrifugation after $10 \mathrm{~min}$ incubation in the NHS. For preparation of cell extracts, the cells were washed with HBSS (Sigma) and mixed with lysis buffer $(0.77 \%$ Triton $\mathrm{X}-100$ in $100 \mathrm{mM}$ Tris, $\mathrm{pH}$ 7.5, $40 \mu \mathrm{l} / \mathrm{ml}$ protease inhibitor cocktail ("Complete", Roche, Mannheim, Germany), 10 $\mathrm{mM}$ EDTA $)$ and incubated for $30 \mathrm{~min}$ at $4{ }^{\circ} \mathrm{C}\left(1 \times 10^{6}\right.$ cells/ml lysis buffer). Next, the lysed cell extract was cleared by centrifugation $\left(18,000 \times g, 15 \mathrm{~min}, 4{ }^{\circ} \mathrm{C}\right)$ and the supernatant was collected and kept frozen at $-80^{\circ} \mathrm{C}$.

\section{RNA interference}

K562 cells were transiently transfected with siRNA by electroporation. Cells were suspended in electroporation buffer (20 mM PIPES, pH 7.0, $128 \mathrm{mM}$ potassium glutamate, $10 \mu \mathrm{M}$ calcium acetate, $2 \mathrm{mM}$ magnesium acetate in RPMI growth medium). The siRNA was added first into sterile electroporation cuvettes (Cell projects, Kent, UK) and then the cells were added and kept on ice for $10 \mathrm{~min}$. Following electroporation in a BTX ECM 830 Electroporator (Harvard Apparatus, Holliston, MA) $(1500 \mu \mathrm{F}$, $250 \mathrm{mV}$ ), the cells were grown for 2 days in their culture medium before examination. Human mortalin siRNA (AUUGUAUUCUCCGAGUCAGUU) and a non-specific siRNA (ACUCUAUCUGCACGCUGACUU) (Dharmacon, Lafayette, $\mathrm{CO}$ ) were used.

\section{Western blotting}

Proteins were diluted in sample buffer $(187 \mathrm{mM}$ Tris$\mathrm{HCl}, \mathrm{pH} 6.8,30 \%$ glycerol, 9\% SDS, 1\% Bromophenol blue), heated at $95^{\circ} \mathrm{C}$ for $5 \mathrm{~min}$, and then subjected to SDS-polyacrylamide gel electrophoresis (SDS-PAGE) over $10 \%$ or $3-10 \%$ acrylamide. Next, the proteins were transferred from the gel to a nitrocellulose membrane and the membrane was blocked with 5\% skim milk in TBS for $1 \mathrm{~h}$ in room temperature. Then, the membranes were incubated with mouse anti-mortalin or anti-Hsp90 $\beta$ antibody in TBS containing 1\% skim milk overnight at
$4{ }^{\circ} \mathrm{C}$. The membrane was washed with TBS containing $0.5 \%$ Tween-20 and incubated with a secondary peroxidase-conjugated goat anti-mouse IgG antibody for $1 \mathrm{~h}$ at room temperature. Finally, the membrane was reacted with Supersignal West Pico Chemiluminescent Substrate (Pierce, Rockfold, IL) for $5 \mathrm{~min}$ and exposed to an X-ray film. The optical density of the bands was quantified after scanning by analysis with the ImageJ software (NIH, Bethesda, MD).

\section{Analysis of protein interactions by ELISA}

Wells of 96-well plate (Nunc, Thermo Fisher Scientific, Rochester, NY) were coated with purified C9 or mortalin or bovine serum albumin (BSA, Sigma) in TBS buffer (10 $\mathrm{mM}$ Tris- $\mathrm{HCl}, \mathrm{pH} 7.5,150 \mathrm{mM} \mathrm{NaCl}$ ) overnight at $4{ }^{\circ} \mathrm{C}$. The wells were washed with TBS containing $0.5 \%$ Tween20 and blocked for $1 \mathrm{~h}$ at $37^{\circ} \mathrm{C}$ with TBS containing $1.5 \%$ BSA. Next, either mortalin or C9 or cell lysate was added for $1 \mathrm{~h}$ at $37^{\circ} \mathrm{C}$. After washing, the first detecting antibody was added for $1 \mathrm{~h}$ at $37^{\circ} \mathrm{C}$. The secondary peroxidaselabeled antibody was then added for $1 \mathrm{~h}$ at room temperature. Binding was quantified with TMB One Component Microwell substrate and TMB Stop solution (Southern Biotech, Birmingham, AL) and analyzed in an ELISA plate reader at $450 \mathrm{~nm}$.

\section{Analysis of protein interactions by density sedimentation}

Proteins in TBS buffer (10 mM Tris- $\mathrm{HCl} \mathrm{pH} \mathrm{7,} 150 \mathrm{mM}$ $\mathrm{NaCl}$ ) were mixed and incubated for $1 \mathrm{~h}$ at $37^{\circ} \mathrm{C}$. Then, the proteins were layered on top of $13 \mathrm{ml}$ of $1-20 \%$ sucrose gradient in TBS in an ultra-centrifugation nitrocellulose tube and subjected to centrifugation $(132,000 \times$ $g, 18 \mathrm{~h}, 4^{\circ} \mathrm{C}$ ) in a Beckman Ultracentrifuge (Fullerton, $\mathrm{CA})$. Fractions $(0.3 \mathrm{ml})$ were collected from the top of the gradient using Auto Densi-Flow fractionator (Labconco, Kansas city, MO) and a Pharmacia Biotech RediFrac fraction collector. Samples $(80 \mu \mathrm{l})$ from each fraction were blotted onto a nitrocellulose membrane in a Bio-Dot Microfiltration Apparatus (Bio-Rad, Hercules, CA) and proteins were detected with antibodies directed either to Hsp90 $\beta$ or C9, followed by peroxidase-conjugated secondary antibodies and development with Supersignal West Pico Chemiluminescent Substrate. The optical density of the dots was quantified as described for western blotting.

\section{Analysis of protein interactions by co- immunoprecipitation}

K562 cell lysates were first treated overnight with protein A/G agarose beads (Santa Cruz Biotechnology, Santa Cruz, CA) in TBS at $4{ }^{\circ} \mathrm{C}$. All procedures described were performed on a rotating platform. Then, the agarose beads were removed from the cell lysates by centrifugation. In parallel, fresh protein $\mathrm{A} / \mathrm{G}$ agarose was incubated 
overnight with either monoclonal mouse anti-Hsp90 $\beta$ or with mouse IgG. Then, the antibody-bearing beads were blocked with $3 \%$ BSA in TBS for $1 \mathrm{~h}$ at room temperature. Next, the pre-cleared lysates were mixed with the antibody-coated beads and incubated for $2 \mathrm{~h}$ at room temperature. The beads were washed four times with TBS, suspended in SDS-PAGE sample buffer, warmed to $95^{\circ} \mathrm{C}$ for $5 \mathrm{~min}$, and bound proteins were removed from the beads for analysis by SDS-PAGE and western blotting.

\section{Statistical analysis}

The experiments were conducted in duplicates, each repeated at least three times. The results are presented as means \pm SD. Statistical significance was determined by using the two-tailed and unpaired Student's $t$ test. Multiple group comparison was calculated by one-way ANOVA. Two-way ANOVA was performed to compare two groups, a tested reagent and the interaction between them. GraphPad Prism 5 was used. Statistical significance was assumed when the $P$ value was smaller than 0.05 .

\section{Acknowledgements}

This research was supported in part by grants from the Israel Science Foundation and the Israel Cancer Association.

\section{Conflict of interest}

The authors declare that they have no conflict of interest.

\section{Publisher's note}

Springer Nature remains neutral with regard to jurisdictional claims in published maps and institutional affiliations.

Received: 18 May 2017 Revised: 14 December 2017 Accepted: 18 December 2017

Published online: 02 February 2018

\section{References}

1. Muller-Eberhard, H. J. The membrane attack complex. Springer Semin. Immunopathol. 7, 93-141 (1984).

2. Ricklin, D., Hajishengallis, G., Yang, K. \& Lambris, J. D. Complement: a key system for immune surveillance and homeostasis. Nat. Immunol. 11, 785-797 (2010).

3. Morgan, B. P., Luzio, J. P. \& Campbell, A. K. Intracellular Ca2+ and cell injury: a paradoxical role of $\mathrm{Ca} 2+$ in complement membrane attack. Cell Calcium 7, 399-411 (1986).

4. Ziporen, L., Donin, N., Shmushkovich, T., Gross, A. \& Fishelson, Z. Programmed necrotic cell death induced by complement involves a Bid-dependent pathway. J. Immunol. 182, 515-521 (2009).

5. Gancz, D., Donin, N. \& Fishelson, Z. Involvement of the c-jun N-terminal kinases JNK1 and JNK2 in complement-mediated cell death. Mol. Immunol. 47, 310-317 (2009).

6. Merle, N. S., Church, S. E., Fremeaux-Bacchi, V. \& Roumenina, L. T. Complement system part I - molecular mechanisms of activation and regulation. Front. Immunol. 6, 262 (2015).

7. Fishelson, Z., Donin, N., Zell, S., Schultz, S. \& Kirschfink, M. Obstacles to cancer immunotherapy: expression of membrane complement regulatory proteins (mCRPs) in tumors. Mol. Immunol. 40, 109-123 (2003).

8. Zell, S. et al. Down-regulation of CD55 and CD46 expression by anti-sense phosphorothioate oligonucleotides (S-ODNs) sensitizes tumour cells to complement attack. Clin. Exp. Immunol. 150, 576-584 (2007).
9. Donin, N. et al. Complement resistance of human carcinoma cells depends on membrane regulatory proteins, protein kinases and sialic acid. Clin. Exp. Immunol. 131, 254-263 (2003).

10. Moskovich, O. \& Fishelson, Z. Live cell imaging of outward and inward vesiculation induced by the complement C5b-9 complex. J. Biol. Chem. 282, 29977-29986 (2007).

11. Pilzer, D. \& Fishelson, Z. Mortalin/GRP75 promotes release of membrane vesicles from immune attacked cells and protection from complementmediated lysis. Int. Immunol. 17, 1239-1248 (2005).

12. Wadhwa, R., Taira, K. \& Kaul, S. C. An Hsp70 family chaperone, mortalin/ mthsp70/PBP74/Grp75: what, when, and where? Cell Stress Chaperon. 7, 309-316 (2002).

13. Bhattacharyya, T. et al. Cloning and subcellular localization of human mitochondrial hsp70. J. Biol. Chem. 270, 1705-1710 (1995).

14. Dundas, S. R., Lawrie, L. C., Rooney, P. H. \& Murray, G. I. Mortalin is overexpressed by colorectal adenocarcinomas and correlates with poor survival. J. Pathol. 205, 74-81 (2005).

15. Takano, S. et al. Elevated levels of mortalin expression in human brain tumors. Exp. Cell Res. 237, 38-45 (1997).

16. Chen, J. et al. Overexpression of mortalin in hepatocellular carcinoma and its relationship with angiogenesis and epithelial to mesenchymal transition. Int. J. Oncol. 44, 247-255 (2014).

17. Pilzer, D., Saar, M., Koya, K. \& Fishelson, Z. Mortalin inhibitors sensitize K562 leukemia cells to complement-dependent cytotoxicity. Int. J. Oncol. 126, 1428-1435 (2010).

18. Saar Ray, M., Moskovich, O., losefson, O. \& Fishelson, Z. Mortalin/Grp75 binds to complement C9 and plays a role in resistance to complement-dependent cytotoxicity. J. Biol. Chem. 289, 15014-15022 (2014).

19. Mayer, M. P. \& Le Breton, L. Hsp90: breaking the symmetry. Mol. Cell 58, 8-20 (2015).

20. Johnson, J. L. Evolution and function of diverse Hsp90 homologs and cochaperone proteins. Biochim. Biophys. Acta 1823, 607-613 (2012).

21. Nollen, E. A. \& Morimoto, R. I. Chaperoning signaling pathways: molecular chaperones as stress-sensing 'heat shock' proteins. J. Cell Sci. 115, 2809-28016 (2002).

22. Chen, B., Piel, W. H., Gui, L., Bruford, E. \& Monteiro, A. The HSP90 family of genes in the human genome: insights into their divergence and evolution. Genomics 86, 627-637 (2005).

23. Felts, S. J. et al. The hsp90-related protein TRAP1 is a mitochondrial protein with distinct functional properties. J. Biol. Chem. 275, 3305-3312 (2000).

24. Sorger, P. K. \& Pelham, H. R. The glucose-regulated protein grp94 is related to heat shock protein hsp90. J. Mol. Biol. 194, 341-344 (1987).

25. Richardson, P. G. et al. Inhibition of heat shock protein 90 (HSP90) as a therapeutic strategy for the treatment of myeloma and other cancers. Br. J. Haematol. 152, 367-379 (2011)

26. Eustace, B. K. et al. Functional proteomic screens reveal an essential extracellular role for hsp90 alpha in cancer cell invasiveness. Nat. Cell Biol. 6, 507-514 (2004).

27. Neckers, L. Heat shock protein 90: the cancer chaperone. J. Biosci. 32, 517-530 (2007).

28. Li, C. F. et al. Heat shock protein 90 overexpression independently predicts inferior disease-free survival with differential expression of the alpha and beta isoforms in gastrointestinal stromal tumors. Clin. Cancer Res. 14, 7822-7831 (2008).

29. Kang, B. H. et al. Regulation of tumor cell mitochondrial homeostasis by an organelle-specific Hsp90 chaperone network. Cell 131, 257-270 (2007).

30. Jhaveri, K. et al. Heat shock protein 90 inhibitors in the treatment of cancer: current status and future directions. Expert Opin. Invest. Drugs 23, 611-628 (2014).

31. Sreedhar, A. S., Nardai, G. \& Csermely, P. Enhancement of complementinduced cell lysis: a novel mechanism for the anticancer effects of Hsp90 inhibitors. Immunol. Lett. 92, 157-161 (2004).

32. Tschopp, J. Circular polymerization of the membranolytic ninth component of complement. Dependence on metal ions. J. Biol. Chem. 259, 10569-10573 (1984).

33. Prodromou, C. et al. Identification and structural characterization of the ATP/ ADP-binding site in the Hsp90 molecular chaperone. Cell 90, 65-75 (1997).

34. Schulte, T. W. et al. Antibiotic radicicol binds to the N-terminal domain of Hsp90 and shares important biologic activities with geldanamycin. Cell Stress Chaperon. 3, 100-108 (1998). 
35. Papadimitriou, J. C., Drachenberg, C. B., Shin, M. L. \& Trump, B. F. Ultrastructural studies of complement mediated cell death: a biological reaction model to plasma membrane injury. Virchows Arch. 424, 677-685 (1994).

36. Park, H. K., Lee, J. E., Lim, J. \& Kang, B. H. Mitochondrial Hsp90s suppress calcium-mediated stress signals propagating from mitochondria to the ER in cancer cells. Mol. Cancer 13, 148 (2014).

37. Guo, W. et al. Targeting GRP75 improves HSP90 inhibitor efficacy by enhancing p53-mediated apoptosis in hepatocellular carcinoma. PLoS ONE 9 e85766 (2014).

38. Takano, S., Wadhwa, R., Mitsui, Y. \& Kaul, S. C. Identification and characterization of molecular interactions between glucose-regulated proteins (GRPs) mortalin/GRP75/peptide-binding protein 74 (PBP74) and GRP94. Biochem. J. 357, 393-398 (2001)

39. Gancz, D. \& Fishelson, Z. Cancer resistance to complement-dependent cytotoxicity (CDC): Problem-oriented research and development. Mol. Immun. 46 , 2794-2800 (2009)

40. Echeverria, P. C., Bernthaler, A., Dupuis, P., Mayer, B. \& Picard, D. An interaction network predicted from public data as a discovery tool: application to the Hsp90 molecular chaperone machine. PLOS ONE 6, e26044 (2011)
41. Chae, Y. C. et al. Landscape of the mitochondrial Hsp90 metabolome in tumours. Nat. Commun. 4, 2139 (2013).

42. Wadhwa, R. et al. Identification and characterization of molecular interactions between mortalin/mtHsp70 and HSP60. Biochem. J. 391, 185-190 (2005).

43. Ghosh, J. C., Siegelin, M. D., Dohi, T. \& Altieri, D. C. Heat shock protein 60 regulation of the mitochondrial permeability transition pore in tumor cells. Cancer Res. 70, 8988-8993 (2010).

44. Fishelson, Z., Hochman, I., Greene, L. E. \& Eisenberg, E. Contribution of heat shock proteins to cell protection from complement-mediated lysis. Int Immunol. 13, 983-991 (2001)

45. Schlesinger, M., Nave, Z., Levy, Y., Slater, P. E. \& Fishelson, Z. Prevalence of hereditary properdin, $C 7$ and $C 8$ deficiencies in patients with meningococcal infections. Clin. Exp. Immunol. 81, 423-427 (1990).

46. Mollnes, T. E., Lea, T., Harboe, M. \& Tschopp, J. Monoclonal antibodies recognizing a neoantigen of poly(C9) detect the human terminal complement complex in tissue and plasma. Scand. J. Immunol. 22, 183-195 (1985). 